\title{
Some Political Issues Related to Future Special Nuclear Materials Production
}

\author{
A. T. Peaslee, Jr.
}

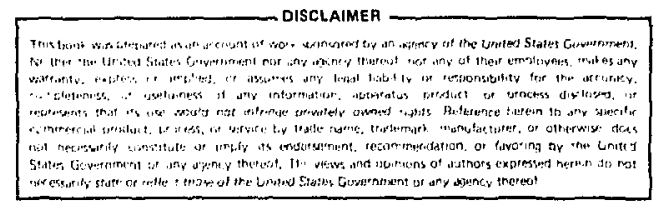

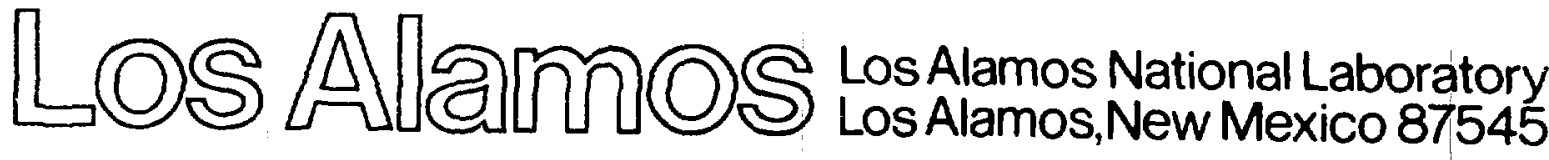


SOME POL ITICAL ISSUES RELATED TO FUTURE

SPECIAL NUCLEAR MATERIALS PRODUCTION

by

A. T. Peaslee, Jr.

\begin{abstract}
The Federal Government must take action to assure the future adequate supply of special nuclear materials for nuclear weapons. Existing statutes permit the construction of advanced defense production reactors and the reprocessing of commercial spent fuel for the production of special materials. Such actions would not only benefit the US nuclear reactor manufacturers, but also the US electric utilities that use nuclear reactors.
\end{abstract}

\title{
EXECUTIVE SUMARY
}

Positive action by the Federal Government is necessary to provide special nuclear materials production to assure the continued effectiveness of US nuclear weapons. He explore the inssitutional and societal issues associated with such action in three nonexclusive options. The first option is merely a renovation of existing facilities and has already been started. The second option would construct advanced defense production reactors at the present Federal reservations, thus offering hope of preserving the competitive edge of US nuclear reactor manufacturers. The third option would involve Federa? reprocessing of commercial spent fuel, thereby saving US commerciat nuclear power generation from extinction by breaking the reprocessing impasse.

None of these options is contrary to present statutes, but all involve political controversy. The antinuclear-power, antinuclear-weapons, an tibig-business, antimilitary, and arms-control communities can be expected to form a coalition. Confrontations and demonstrations can be expected by activist groups at nuclear weapons installations such as the Rocky Flats Plant. 
I. INTRODUCTION

A. Background

Since the formation of the US Atomic Energy Commission (AEC) in 1947, the production of the special nuclear materials used in nuclear weapons has been under civilian agency control as required by the Atomic Energy Act of 1954 as amended. This civilian agency control has continued through the AEC's successor agencies, the Energy Research and Development Administration (ERDA) and the Department of Energy (DOE). The military services, however, profoundly influence production deci:ions. Production of two special nuclear materials-plutonium and tritium-are considered in this study. Both materials are extracted from materials irradiated in the defense production nuclear reactors.

At present, there are three defense production reactors (the $P, K$, and $C$ Reactors) producing weapons-grade plutonium* and tritium at the Savannah River Plant near Aiken, South Carolina. ${ }^{\star}$ Associated with these reactors are three chemical processing plants that extract the special nuclear materials; namely, Purex-F, Purex-Fi, and 232-H. According to plans, an additional reactor (the $L$ Reactor) will be restarted. The $N$ Reactor and its associated chemical processing plant, Purex, are at the Hanford, Washington, installation. Although this reactor presently is producing fuel-grade plutonium, and al though the Purex plant has been in standby condition for almost a decade, the $N$ Reactor is scheduled to be converted to weapans-grade plutonium production, and the Purex plant is scheduled to be reactivated. ${ }^{2}$ An integral part of the production of plutonium for nuclear weapons is the chemical and metallurgical processing facilities located at the Rocky flats Plant in Denver, Colorado. These facilities can remove chemical impurities, such as americium, that grow into plutonium by radioactive decay (Ref. 3, p. 11$)$.

\footnotetext{
Weapons-grade plutonium contains $6 \%$ impurity of the plutonium isotope 240 , fuel-grade plutonium has 12\%, and reactor-grade plutonium has about 20-30\%.

* The current status of the US special nuclear materials production complex was given by Dr. F. Charles Gilbert, Director, Office of Muclear Materials Production, DOE, in Congressional testimoriy (Ref. 1, p. 46).
} 
The military requirements for $\mathrm{nh}$..ear weapons come from the Department of Defense (DOD) document known as the "Stockpile Memorandum." This document, as it existed in June 1980, gave 3 years of definitive weapons production authority to the DOE (FY80-FY82), authority for purchasing long lead-time items for the next 2 fiscal years (FY83 and FY84), and guidance for planning purposes for the next 3 fiscal years (FY85-FY87). Thus, the Stockpile Memorandum forecasts the military requirsments for nuclear weapons production to some degree of detail with an 8-year horizon (Ref. 3, p. 6).

The defense production reactor facilities are more than a quarter of a century old. Their ability to meet military production requirements in the years beyond the horizon of the Stockpile Memorandum was questioned in a hearing before the Procurement and Military Nuclear Sys tems Subcomittee of the Committee on Armed Services of the US House of Representatives in June $1980 .^{\text {' }}$

Duane $C$. Sewe11, then Ass istant Secretary of Energy for Tense Programs of DOE, testified that "... the current budget will permit us to meet DOD requirements through $F Y 1985$ with the nuclear materials production we have. If you go beyond that point and assume that those $i$ tems stated for planning purposes are actually going to be produced, ... we fall short ... in FY 1988." (Ref. 3, p. 6.) General Lew Allen, USAF, presented the views of the Joint Chiefs of Staff (JCS) with regard to the adequacy of the military production reactors by saying,

"The second concern was really more fundamental on our (JCS) part, and it is the concern that the basic production capabilities of the Department of Energy are aging, tend to be single threat, that is, not sufficiently redundant to be able to handle technical problems, and lacking an expansion capability which, after the Afghanistan situation, seemed to us to be prudent to consider." [Ref. 3, p. 9.]

Thus, both the consumer (DOD as represented by the JCS) and the producer (DOE) of reactor-produced special nuclear materials are concerned whe ther the existing US production facilities can handle the military requirements beyond the 8-year horizon of the Stockpile Memorandum.

\section{B. Assumptions}

The basic assumption of this study is that the DOE will have to take some sort of positive action to ensure that the future military needs for 
plutonium and tritium will be met. is bound this study, three options are postulated for the DOE.

Qption 1. Replace or restore the existing military production reactors at their present locations using the existing technology.

Option 2. Replace the defense production reactors at the present sites with new reactors employing technologies that have direct commercial power applications.

Option 3. Utilize reactor products and reactor capacity from commercial power reactors and employ a special isotope separation (SIS) process to produce special nuclear materials for nuclear weapons.

These three options are by no means exhaustive or mutually exclusive. They cover a wide spectrum as far as institutional and societal impacts are concerned. This study will focus on likely issues that might arist from the choice of each of these options.

\section{OPTION 1}

\section{A. Scope}

Option 1 can be characterized as the restoration of the status quo ante. For example, to change the $N$ Reactor at Hanford to the production of weapons-grade rather than fuel-grade plutoniun means doubling the rate at wich the reactor fuel is put through the reactor. There is no change to the reactor as such, just to the rate at wich the fuel is cycled through the reactor. The Purex $\mathrm{plant}$ at $\mathrm{H}$ anford has been maintained in a nearly operating condition since it went on standby service in 1972, but it would take 3.5 years and a $\$ 100-m i l l i o n$ refurbishment effort to get the Purex plant back into full operation.

At the Savannah River Plant, somewhat more effort is required to bring the two defense production reactors, $L$ and $R$, that are in standoy condition in to production. 
"Reactivation of the $L$ Reactor would take about two years and cost about $\$ 90$ million. The estimated cost to reactivate $R$ Reactor is $\$ 180$ million, and this effort would take about three years ....* The $L$ Reactor was placed in standby in 1968 and $R$ Reactor in 1964. $A$ post-shutdown inspection of $R$ Reactor revealed stress corrosion cracking in the reactor cooling water intake nozzles. Repair of these cracks would necessitate removal of part of the reactor vessel concrete shield, vessel decontamination, grinding out of cracks or nozzle replacement, and weld preparation and repair.

"During the restart period, it would be necessary to hire and train reactor operators and support personnel; replace the reactor's primary heat exchangers and pumps, steam boilers, and control instrumentation; and install dual safety and dual process control computers in both $L$ Reactor and $R$ Reactor. In addition, the control rods, safety rods, and motor generator sets for R Reactor would have to be replaced.

"The Savannah River chemical processing facilities could accommodate the extra weapons-grade plutonium produced in $L$ Reactor if existing steam boilers were upgraded. However, if $R$ Reactor were on-line at the same time, additional steam capacity would be required." [Ref. 1, p. 145.]

Option 1 can thus be viewed os bringing part of the defense production reactor complex to former operating condition, an action that might be termed just "proper ma intenance" by proponents of Option 1.

\section{B. Local and Regional Citizen Reaction}

The above activities would hardly be unwelcome in the communities that surround the existing Federal reservations at Hanford and Savannah River. The prospect of additional economic well-being for these communities, which has been called the "Halo Effect," 4 can be expected to more than offset any qualms about radiation exposure risk or other fears. After all, people in these comminities have become accustomed to defense production reactors. If, however, the DOE should propose to start defense profuction reactor activities at new locations, one would expect citizens near the Hanford and Savannah Riyer reservations to object, as well as citizens at a proposed new location, albeit for different reasons.

*These estimates now appear optimistic according to a private conversation with W. F. Rich of Los Alamos National Laboratory, March 24, 1981. 
The citizens of the Pacific Northwest as a whole may be expected to welcome any activity that would insure the coritinuation of the $N$ Reactor, because the reactor is now providing by-product steam to the State of Wash ington Public Power Supply System (WPPSS). That steam, in turn, generates 3.9 billion khth of electricity per year for the Bonneville Power Administration power grid (Ref. 1, p. 46). Loss of this electric power would seriously impact an already electric-power-starved region; the industries served by the Bonneville Power Administration would almost certainly face a curtailment of activities if the $\mathrm{N}$ Reactor were not operated at capacity.

The continuation of defense production reactor operations should assure the citizens in the Hanford and Savannah River regions that the Federal Government will continue to give high visibility and support to nuclear waste mana gement.

C. Institutional Requirements

The very size of the needed repairs and restorations, however, opens the door to possible harassment and delay by court actions.

"Reactivation of these reactors may be considered a major Federal action as defined by the National Environmental Policy Act (NEPA) and, as such may require preparation and distribution of an environmental impact statement (EIS) for public conment. Restart. of these reactors could be $h$ indered by 1 awsuits until the adequacy of the EIS is acted on hy the courts." [Ref. 3, p. 145.]

Those option 1 changes in the defense production reactor compiex may trigger intervenor actions based on environmental impact. Muclear Regulatory Commission (NRC) licensing of these activities is certainiy not needed and should not be condoned. Section 110 of the Atomic Energy Act of 1954, as amended, specifically excludes the requirement for licensing the "processing, fabricating, or refining of special nuclear material, or the separation of special nuclear material from other substances, under contract with and for the account of the Commission (AEC). "5 Any abandonment of this "grandfather clause" on the part of the administration can be expected to result in the effective curtailment of defense production reactor activities.

Under the requirements of Sec. 36 of the Arms Control arid Disarmament Act, which was enacted in $1975,{ }^{6}$ an Arms Control Impact Statement (ACIS) would have to be filed with the budgetary request to Congress for Option 1. 
The ACIS reports to Congress the results of an interagency study on the effect of proposed programs that influence national security on arms control and disarmament policy. An ACIS, al though possibly a burden on DOE insofar as participation in the interagency process for generating an ACIS is concerned, should have no impact on Option 1.

D. Other Issues

It is impossible to forecast, with any degree of certainty, which issues will become important in the public arena wen any action is taken on the production of special nuclear materials or where such issues ma lead to confrontations. The topic of special nuclear materials production has the possibility of attracting attention not oniy from those who desire general or nuclear disarmament, regardless of the consequences, but also from those who are against nuclear power or modern technology in general. Al though there seems to be a clear national defense requirement for special nuclear material production, there are several groups that might "raise a public fuss" about nuclear power or unilateral nuclear disarmament if Option 1 were chosen. Two conceivable issues that might surface are the question of enhanced activity at the Rocky flats Plant and the question of a special nuclear materials production cutoff.

An old US initiative to hait the growth of nuclear weapon stockpiles is the proposal made by President Eisemower in his letter of March 1, 1956, to USSR Premier Bulganin.

"In my judgment, our efforts must be directed especially to bringing under control the nuclear trreat. As an important step for this purpose and assuming the satis factory operation of our air and ground inspection system, the United States would be prepared to work out, with other nations, suitable and safeguarded arrangements sc that future production of fissionable materiais anywhere in the world would no longer be used to increase the stockpiles of explosive weapons." [REf. 7.]

On September 25, 196?, the cutoff of fissionable material production was proposed by the US to the United Nations as part of a program for general and complete disarmament. ${ }^{8}$ With the successful appearance of the Nuclear Non-Proliferation Treaty (NMPT), the issue of fissionable material production cutoff has taken a back seat in international affairs. Hot restoring the defense production ractor complex and letting it deteriorate into a 
nonoperating condition, ipso facto, would cut off the production of fissionable material for nuclear weapons. If such a course of inaction were followed, no new plutonium-bearing weapons could be made unless older plutonium-bearing weapons were retired and the plutonium they contained were recycled.

The public sector of the disarmament community has generally ignored another facet of a special nuclear materials production cutoff; namely, that all nuclear weapons dependent upon tritium for successful operation will decay to some extent just as tritium decays.* Besides nuclear weapons that might depend on tritium-driven thermonuclear reactions for a major part of their

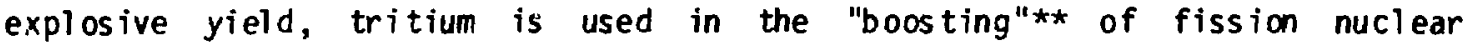
weapons. At present, tritium for nuclear weapons use is produced only at the Savannah River Plant, al though coproduction of tritium and plutonium $c$ lld be accomplished at the Hanford $N$ Reactor (Ref. 3, p. 145). Thus, a cutoff of special nuclear materials production at the defense production reactors would mean the certain disablement, in approximately a decade, of one-half of the nuclear weapons stockpile that uses tritium. Such a prospect wculd probably be attractive to the followers of the "disarm regardless" politicui stripe.

The activity in the Rocky flats Plant will naturally increase when the new weapons-grade plutonium starts appearing. Even during the several years it takes to exercise Option 1 and start the production of new weapons-grade plutonium, however, there will be additional activity at the Rocky flats Plant. Because some of the plutonium being retired from nuclear weapons is not suitable for incorporation in new nuclear weapons, that plutonium must be chemically purified at the Rocky flats Plant.

"... (the) question had to do with plutonium that was identified as unusable in the $s$ tockpile report. I bel ieve you are referring to the material that is weapons-grade, but in a condition that $i t$ needs to be purified, to have certain contaminant materials taken out of it. Americium is one that grows in as the material ages, and another is gallium, wich is one of owe stabilizing elements that we put in.

*Tritium decays with a 12.26 year half-life, which corresponds to roughly a $5.7 \%$ rate of annual disappearance.

* "Boosting" is the enhancement of a fission reaction by thermonuclear neutrons where the energy released in the thermonuclear reaction is a small fraction of the total. Tritium is used in boosting. 
"You are correct that in the early years up to 1985, there is a considerable amount of material that is not directly usable in weapons production in the form that it exists today. It does have to go through this chemical processing to put it into a useable form.

"The plant at Rocky Flats does have a new building that has been dedicated, and it will come on line in the second quarter of 1982 . The building will have a large capacity and will be able to handle the problem." $[\operatorname{Re} f .3$, p. 11.]

The Rocky Flats plant is located at the western edge of the Denver metropolitan area. The plant's contribution to the Denver Metropolitan economy is small and there is very little, if any, of the Halo Effect that is found near the Federal reservations at Hanford and Savannah River. In the past, there have been several citizen protests and confrontations over the plutonium processing activities at Rocky fiats, and there is current environmental concern by portions of the colorado state fovernment. 9.10 Possibly, further protests and confrontations may be generated by any increase in plutonium processing at the Rccky Flats Plant.

\section{OPTION 2}

\section{A. Scope}

Option 2 can be characterized as the modrinnization of the defense production reactors and not jist the restorative action of Option 1 . By replacing the defense production reactors with modern reactors, the DOE wocild benefit from the previous quarter century of progress in reactor technology. By locating the new reactors at the present Federal reservations at Hanford and Savannah River, the DOE would be able to capitalize on the Halo Effect to minimize adverse reactions of 1 ocal and regional populations. The other issues that pertain to Option 1 would also apply to Option 2, al though the degree of applicability is different. Assuming that the reactor technology selected in Option 2 has direct comnercial power reactor applications, there is the additional benefit of providing welcome business for the domestic nuclear reactor manufacturers; however, there would also be the certainty of generating great opposition from the arms-control community.

B. Commercial Benefits

The current outlock for reactor orders in the $1990 \mathrm{~s}$ is bleak. 11 The opportunity to build defense production reactors would allow domestic reactor 
manufacturers a chance to preserve their design teams and construction capabilities. Even if only one new defense production reactor were built, it would allow at least one domestic concern to benefit and perhaps to survive. The competition to build a reactor under option 2 should be extremely intense. Option 2 would permit the building of a reactor without first having the design publicly dissected and debated before the NRC, because the "grandfather clause" in the Atomic Energy Act would provide an exemption from the licensing requirement. If the technology to be employed in Option 2 were to be transferred to the private commercial-power market, it would have to go through the NRC licensing procedure. Having a similar successful reactor operating under the DOE azgis could be a great help in obtaining a license.

The question of how much technoloqv could be transferred from the defense production reactor to the private commercial power sector has been addressed by the General Atomic Company, assuming that their reactor candidate, the High Temperature Gas Cooled Reactor (HTGR), was chosen for the replacement production reactor (RPR).

"The benefits to the civilian HTGR program enanating from the HTGR-RPR are great as we see it. This benefit is frimarily based on the carryover of design and development activities, on the order of $80 \%$, for the HTGR-RPR case to the civilian case. This, in our interpretation, provides a substantial added basis to pursue the HTGR-RPR pro.ject." [Ref. 12.]

Manufacturers of competing candidate reactors have undoubtedly also addressed this question with much the sare result.

The question of whether the choice of a given commercial reactor technology for option 2 will inhibit the future foreign sales of that reactor has been answered by the General Accounting office.

"A number of countries are proceeding toward commercial development of advanced nuclear technology, such as breeder reactors and the fuel-reprocessing facilities to sustain them. They view breoder reactors as a future means of increased energy independence. US companies in the past were encouraged to pursue this advanced technology; however, the present ban on its commercial application for nonproliferation reasons has caused the United States to lag behind other countries. This could only hurt the ability of US companies to participate in future nuclear markets." [Ref. 13.]

Thus, the Option 2 selection of an advanced reactor design is thought to be beneficial to domestic reactor manufacturers. 
The choice of Option 2 should generate determined opposition by those who disfavor nuclear power. Groups such as Critical Mass, Center for Science in the Public Interest, Environmental Action Foundation, Friends of the Earth, ivatural Resources Defense Council, Task Force Against Muclear Pollution, Public Citizen, Plolic Citizen Action Group, Sierra Club, Union of Concerned Scientists, and others* might intervene through court actions concerning the adequacy of environmental impact statements that would undoub tedl $y$ have to be filed under the NEPA if Option 2 were selected. Such groups would also be joined in opposition by the arms ontrol community, which is resolutely opposed to any lower ing of the barrier between military and commercial nuclear power.

C. Arms Con trol I $1554 e s$

Unlike the Option 1 Arms Control Impact Statement (ACIS) that should cause little or no reaction, the cption 2 AcIS can be counted on to raise a storm of protest and much concern both with in and without concress. The basic reason is that one of the shibboleths of the arms control community is the firm conviction that military and civilian applications of nuclear energy must remain separato and distinct to prevent, or at least inthibit, the spread of nuclear weapons to more nations. The report of the Nonproliferation Al ternative Systems Assessiment Promaln (NASAP) provides a su.cinct summary of this ar qumen $t$.

"The problem of proliferation is the danger posed by the movement toward or acquisition of a nuclear-weapons capability by a nation or subnational group presently without it. This danger would be a ggravated by the similarity of the nuclear materials and facilities involved in similar processes of developing either nuclear nowor or nuclear-weapons capabilities. in turn, these similarities can make the rea? purpose of a nuclear development ambiguous throughout much of the process. The decision to acquire a nuclear-weapons capability may be faced at any time in the course of this development and is influenced by three primary considerations. These are the =1!pply of materials, facilities, and expertise; the demand for weapons; and the would-be proliferator's perceptions of the political and military risks entailed, that is, the risk of detection and response by one or more nations, or by the international community as a whole.

${ }^{\star} A$ representative selection of the views of those opposed to nuclear power can be found in Refs. 14-18. 
"In facing the complex decision to move toward or acquire nuclear weapons, a nation or a subnational group is likely to choose a course of action that ensures the greatest chance of success at the least risk of detection and response. Where there is a choice, it is between an independent military capability and an abuse of civilian facilities. As the development of a nuclear power program overlaps the development of a ruclear weapons program and is recognized as legitimate, so a decision to acquire a nuclear weapons capability can be implemented with reduced political and military risks. If all actions are legitimate, the risks are minimized because all actions are justifiable in terms of their nonmilitary purposes.

"For this reason, proliferation resistance focuses upon the degree to which overlap between military and civilian nuclear power programs may be prevented or reduced. Wiere the two programs do not overlap, the distance between a civilian nuclear power program and the possession of nuclear weapons would be appropriately measured by the additional resources and time involved a fter a nation makes a commitment which violates agreements or conventions of international behavior. The nature of those resources and the time necessary to marshal them productively would help determine the $1 \mathrm{ikel}$ ihood of exposure to risk that a nation runs in moving toward or acquiring a nuclear weapons capability from a starting point in a civilian nuclear program." [Ref. 19.]

Thus the applicability of the Option 2 defense production reactor to civilian nuclear power is an anathema to those whose primary concern is nuclear nonproliferation. *

It is specious, however, to apply this line of reasoning to the US production of special nuclear materials. The US is already a nuclear weapons state and there can be, therefore, no valid concern about nuclear prol iferation. Inherent in applying this line of reasoning to non-nuclear-weapons states is the supposition that there is a fundamental difference between civilian and military nuclear reactors. Any suprosed dichotomy between the civilian and military production of plutonium and tritium is institutional at most. There is no fundamental difference between the plutonium produced for nuclear power or for nuclear weapons. The tritium used in nuclear weapons is the same tritium as might someday be used in a fusion power reactor. The fact

\footnotetext{
*A good expression of the Carter Administration views on this aspect of nonproliferation policy was given by Lawrence Scheinman, Senior Advisor to the Under Secretary of State for Security Assistance, Science and Technology, in his talk, "United States Non-Proliferation Policy," given at the 18th Annuai ASME Symposium, March 16-17, 1978, Albuquerque, New Mexico.
} 
that the Atomic Energy Act codified a difference in the 1 icensing requirements for civilian and military special nuclear materials has already been mentioned. President Eisenhower's "Atoms for Peace" initiative also isolated the commercial fuel cycle from military applications. This initiative was the dominant ingredient of the US nuclear foreign policy from its inception in 1954 through the Indian nuclear explosion in the Rathjathastan Desert in 1974.

one of the myths that was current during these decades, and still pers ists to some extent, was that plutonium created in power reactors was unfit for use in nuclear weapons. Specifically, it was thought that reactorgrade pluionium had such a high concentration of the plutonium isotope 240 that any weapon made from such plutonium would detonate prematurely with no militarily significant yield. This canard was completely exposed by Albert Whlstetter in $h$ is testimony given in the United Kingdom's hearings on nuclear reprocessing at the Windscale and Calder Works. Professor Wohlstetter testified in response to the statement that "Whatever the facts about the usability of reactor-grade plutonium in a nuclear explosive, no country has ever used it." (Ref. 20, f. 55.)

"First, this assertion is simply false. While the exact details are classified, I am able to say that the United States, for example, has exploded a device using reactor-grade plutonium. Second, this argument, especially as recently formulated, is even more meaningless than I have so far suggested, since "reactor-grade plutonium" simply means plutonium that has been produced by long irradiation periods and as a result has a higher plutonium-240 and -242 content." [Ref. 20, p. 38.$]$

Professor Viohlstetter then went on to describe how not uncommon irregularities in the operation of light-water reactors, which are by far the most prevalent commercial nuclear power reactor type, can produce sizeable amounts of weapons-grade plutonium.

It should be manifest to all that there is no technical demarcation between the military and civilian nuclear reactor technology and that there never was one. What has persisted over the decades is just the misconception that such a linkage does not exist. Thus, al though the Option 2 ACIS may create an uproar, sensible debate will help to show that the nonproliferation worries caused by the supposed lowering of the wall between the civilian and mil itary atom are groundless for option 2 . 


\section{OPTION 3}

\section{A. Scope}

Option 3 can be characterized as the marshaling of commercial nuclear power reactor capacity for the production of special nuclear materials. All of the issues pertaining to Options 1 and 2 also apply to a greater extent to Option 3. Additional institutional issues that can be expected from Option 3 are connected with the US Spent Fuel Policy and the agreement between the US and the International Atomic Energy Agency (IAEA) to place certain US civilian nuclear energy facilities under IAEA Safeguards.

Unlike Options 1 and 2, Option 3 also has a significant technological $r$ isk issue associated with it. That technological risk issue involves the feasibility of developing a satisfactory special isotope separation (SIS) process to remove the higher atomic weight isotopes from reactor-grade plutonium to make weapons-grade plutonium. This study assumes that a satisfactory SIS will be developed in time for an Option 3 imp? ementation.

B. Issues Related to US Spent Fuel Policies

The "spent fuel" that is taken from 1 ight-water commercial reactors has lost only about $1-2 \%$ of $i$ ts energy potential as a nuclear fuel.* It has been a basic assumption of the commercial nuclear power industry that the unused part of the nuclear fuel, about $98 \%$ of the original fuel value, would be retrieved for eventual use. Spent fuel storage facilities at nuclear reactor sites were sized with the idea of providing a temporary storage until shipment to reprocessing plants could be made. The projected monetary value of reprocessed fuel has been factored into the financial planning for utilities operating commercial nuclear power plants.

In April 1977, President Carter made permanent the temporary delay in fuel reprocessing ordered by President Ford in October 1976. Utilities were then faced with the problem of whether the spent fuel is reusable and an asset or just waste and a liability. In addition, their temporary storage facilities had a limited capacity that, when reached, would force reactors to shut down.

*The General Ás'snting office has made several excellent - tudies of the US spent nuclear fijel policies. See Refs. 21-23. 
In October 1977, the DOE announced the presidentially approved Spent Fuel Storage Policy. Under this policy, utilities would be permitted to deliver spent fuel at their expense to an approved Federal storage facility for a "nondiscriminatory" charge. Such a charge would be subject to prepayment and would cover all government expenses connected with building and maintaining the storage facilities. Title to the spent fuel would be assumed by the government, and the storage facilities would be licensed by the NRC. Provisions would be made for rebates if fuel reprocessing were ever performed. The Spent Fuel Act of 1979 was submitted to Congress in March 1979 to implement this policy. A "Final Environmental Impact Statement" was released in May 1980. ${ }^{24}$ To date, no legislative action has been taken to implement the above spent fuel policy. If such legislation were to become law, it would seem highiy unlikely that any spent fuel would be handled under this policy because the requirement for NRC licensing would open the door to interminable delays through in tervenor lawsuits.

If Option 3 were selected, it is clear that reprocessing commercial spent fuel to extract piutonium would be embroiled in the controversy over the Carter Administration Spent Fuel Policy. It may be possible, however, to break the impasse by using the need for more special nurslear matarials for nuclear weapons to establish a rational spent fuel policy and industry.

C. US-IAEA Agreement to Sa feguard Certain US Facilities

In December 1967, President Johnson made a commitment to voluntarily place US civilian nuclear facilities under IAEA Safeguards. This commitment, along with the Nuclear Non-Proliferation Treaty, was regarded as being fundamental to the US nonproliferation efforts. It was hoped that the voluntary participation of the US civilian nuclear facilities in IAEA Safeguards would set a good example that might induce proliferators such as India and possibly others to place their facilities under IAEA Safeguards. A side benefit to the US would be the ability to study the effectiveness of the IAEA Safeguards process at first hand. Presidents Nixon, Ford, and Carter have reaffirmed the commitment. The agreement was reached with the IAEA on September 17, 1976.25

Not all US nuclear facilities are subject to IAEA Safeguards, as all facilities with national security interest are specifically excluded. Also, the sheer number of US civilian facilities would be too much of a task for the 
IAEA to safeguard. Therefore, the facilities to be placed under safeguards would be selected by the IAEA from a list of eligible facilities submitted by the US. Holsey G. Handyside, former Deputy Assistant Secretary for International Nuclear and Technical Programs, DOE, testified that the US national security interests would be protected under this agreement.

"US national security interests are fully protected. The United States may at any time, in light of national security considerations, remove facilities from the eligibility list for add facilities to that 1 is $t$ ) or withdraw nuclear material from eligible facilities for transfer to facilities not eligible for IAEA sa feguards." [Ref. 20.]

Thus, the US-IAEA agreement to place certain US facilities under IAEA Sa feguards would not seem to preclude Option 3. Whether the US would actually be willing to tarnish the patina of $i$ ts "good world citizen" image by ramoving national-security-related facilities or materials from the IAEA eligibility list is problematical.

\section{CONCLUSIONS}

There are no legal barriers to any of the options in this study. No legislative relief is required to pursue any or all options. Only budgetary authority and appropriations are required. With the exception of the need for a timely SIS development for Cption 3, there are no technical barriers to these options. There are, however, serious political controversies attached to each option, and the degree of severity is roughly from Option 1 to Option 3.

Besides fulfilling the military needs for special nuclear materials production, Options 2 and 3 can have a profound beneficial effect on the commercial nuclear power industry. In particular, Options 2 and 3, if pursued forthwith, might prevent the foreclosure of the nuclear power option for the US. Option 2 would allow US reactor manufacturers to demonstrate advanced nuclear reactors with the Federal Government assuming much of the "front end" development cost that is now so hard to cover by risk capital. Option 3 would benefit the public utilities that use nuclear reactors by breaking the present impasse on nuclear fuel reprocessing.

The key to successful realization of Options 2 and 3 is the deliberate use of military needs for special nuclear materials production and the "grandfather clause" of the Atomic Energy Act to preclude the delaying and harassing 
tactics of opponents to nuclear power, nuclear weapons, big business, modern technology, and so forth, wose barratry in the past has been so effective in intervenor actions. Firm, decisive, and, above al1, prompt action is needed.

\section{REFERENCES}

1. Testimony of Dr. $\vec{f}$ sha, les Gilbert, Director, office of Nuclear Materials Production, [f,artment of Energy, presented in "Fiscal 1981 DOE Authorization for National Security Programs," Aris Control Subcommittee, US Senate Armid Services Committee, ofth Congress, 2nd Sessior., A. il 28 and June 24. 1980, US Governirent Printing orfice, Washingt, D.C. (1980).

2. The Energy Daiiy (January 20, 1981), p. 2.

3. "Coordination of DOE/DOD Nuclear Materials Requirements," Procurzment and Military Muclear Systems Subcommittee, House Armed Services Committee, 96th Congress, 2ni Session, june 18, 1980, US Government Frinting office, wash ington, D.C. (1980).

4. E. Peelle, "Nuclear Host Communities: Impacts and Responses Reassessed after Three Mile Island," unpublished Cak Ridge Nationai Laboratory Report, December 1979.

5. "Atomic Energy Legisiation Through the 89th Congress, ist Session," Joint Committee on Atomic Energy, US Government Printing Office, Wash ington, D.C. (1965).

6. "Arms Control and Disarmament Act Amendments of 1977," Peport No. 95-219, US House of Representatives, 95 th Congress, 1st Session, US Government Printing office, Washington, D.C. (1977), p. 3.

7. Letter from President Eisenhower to the Soviet Premier (Bulganin), March 1, 1956, Documerit Ho. 151, Documents on Disarmament, 1945-1959, Vol. 1, Department of State, Wash ington, D.C., p. 593.

8. "International Negotiations on the Treaty on the Nonproliferation of Nuclear Weapons," US Arms Control and Disarmament Agency, US Government Printing office, Wash ington, D.C. (January 1969), p. 4.

9. New York Times (Apr i) 30, 1979), D. D8.

10. J. C. Cobb, B. C. Eversole, and P. G. Archer, "weapons Grade P'utonium in Humans Near Rocky Flats," University of Colorado Heal th Sciences Center, oresented at the 52 nd Annual Meeting of the Colorado-Wyoming Academy of Science, April 22-25, 1981, Grceley, Colorado.

11. Energy Users Report (February 5, 1981), p. 253.

12. Letter to A. T. Peasiee from G. B. Lawyer, Manager, HTGR Program Development, General Atomic Company, January 27, 1981. 
13. "US Non-Proliferation Policy: Impact on Exports and Nuclear Industry Could Not Be Determined," US General Accounting office report ID-80-42, US Government Printing office, Washington, D.C. (September 23, 1980). p. 27 .

14. H. Peter Metzger, The Atomic Establishment (Simon and Schuster, New York, 1972).

15. S. Ebbib and R. Kasper, Citizen Groups and the Nuclear Power Controversy: Uses of Scientific and Technological Information (MIT Press, Cambridge, Massachusetts, Ta7dT.

16. The Nuclear Fuel Cycle, Inion of Concerncd Scientists (MIT Press, Cambridge, Massachusetts, 1975 ).

17. R. Hader and J. Abbotts, The Menace of Atomic Energy (Norton, New York, 1977).

18. R. Jungk, The New Jyranny (Grosset and Dunlap, New York, 1979).

19. "Huclear Proliferation and Civilian Nuclear Power: Report of the Nor-Proliferation Alternative Systems Assessment Program," Vol . 1 , DOE /NE-0001, Wash ington, D.C. (1979), p. ?, 3.

20. A. Wohlstetter, Y. Gilinsky, R. Gillette, and P. Wohlstetter, Nuclear rolicies: Fuel Without the Bomb /Ballinger, Cambridge, Massachusetts, T978T, Note 20, p. 55.

21. "The Nation's Muclear Waste-Proposals for Organization and Siting," US General Accounting Office report EMD-79-77, US Government Printing Office. Wash ington, D.C. (June 21, 1979).

22. "Federal Facilities for Storing Spent Nuclear Fuel--Are They Heeded?" US General Azcounting office report EMD-79-82, US Government Printing Office, Washington, D.C. (June 27, 1979).

23. "Nuclear Fuel Reprocessing and the Problems of Safeguarding Against the Spread of Nuclear Weapons," US General Accounting office report QMD-80-38, US Government Printing office, Washington, D.C. (March 18, 1980).

24. "Final Environmental Impact Statement: US Spent Fuel Policy," Yols. 1-5, DOE/EIS-0015, US Government Printing Office, Washington, D.C. (May 1980).

25. "Agreement with the International Atomic Energy Agency for the Application of Safeguards in the United States of America with Protocol," US Senate, Executive B, 95th Congress, 2nd Session, US Government Printing Office, Washington, D.C. (1978).

26. "IAEA Safeguards Agreement," US Senate Foreign Relations Committee, 96 th Congress, ist Session, June 22, 1979, US Government Printing office, Wash ington, D.C. (1979), p. 23. 